\title{
Phytohormone Interaction Modulating Fruit Responses to Photooxidative and Heat Stress on Apple (Malus domestica Borkh.)
}

\author{
Carolina A. Torres ${ }^{1,2 *}$, Gloria Sepúlveda ${ }^{2}$ and Besma Kahlaoui ${ }^{2}$ \\ ${ }^{1}$ Facultad de Ciencias Agrarias, Universidad de Talca, Talca, Chile, ${ }^{2}$ Centro de Pomaceas, Facultad de Ciencias Agrarias, \\ Universidad de Talca, Talca, Chile
}

OPEN ACCESS

Edited by: Vicent Arbona

Jaume I University, Spain

Reviewed by:

Ismail Turkan,

Ege University, Turkey

Andrzej Bajguz,

University of Białystok, Poland

*Correspondence:

Carolina A. Torres

cartorres@utalca.cl

Specialty section: This article was submitted to

Plant Abiotic Stress,

a section of the journal

Frontiers in Plant Science

Received: 01 August 2017 Accepted: 30 November 2017 Published: 14 December 2017

Citation:

Torres CA, Sepúlveda $G$ and Kahlaoui B (2017) Phytohormone

Interaction Modulating Fruit

Responses to Photooxidative and Heat Stress on Apple (Malus domestica Borkh.).

Front. Plant Sci. 8:2129.

doi: 10.3389/fpls.2017.02129
Sun-related physiological disorders such as sun damage on apples (Malus domestica Borkh) are caused by cumulative photooxidative and heat stress during their growing season triggering morphological, physiological, and biochemical changes in fruit tissues not only while it is on the tree but also after it has been harvested. The objective of the work was to establish the interaction of auxin (indole-3-acetic acid; IAA), abscisic acid (ABA), jasmonic acid (JA), salicylic acid (SA), and ethylene (ET) and its precursor ACC (free and conjugated, MACC) during development of sun-injury-related disorders pre- and post-harvest on apples. Peel tissue was extracted from fruit growing under different sun exposures (Non-exposed, NE; Exposed, EX) and with sun injury symptoms (Moderate, Mod). Sampling was carried out every 15 days from 75 days after full bloom (DAFB) until 120 days post-harvest in cold storage $\left(1^{\circ} \mathrm{C},>90 \% \mathrm{RH}\right)$. Concentrations of IAA, ABA, JA, SA, were determined using UHPLC mass spectrometry, and ET and ACC (free and conjugated MACC) using gas chromatography. IAA was found not to be related directly to sun injury development, but it decreased $60 \%$ in sun exposed tissue, and during fruit development. ABA, JA, SA, and ethylene concentrations were significantly higher $(P \leq 0.05)$ in Mod tissue, but their concentration, except for ethylene, were not affected by sun exposure. ACC and MACC concentrations increased until 105 DAFB in all sun exposure categories. During post-harvest, ethylene climacteric peak was delayed on EX compared to Mod. ABA and SA concentrations remained stable throughout storage in both tissue. JA dramatically increased post-harvest in both EX and Mod tissue, and orchards, confirming its role in low temperature tolerance. The results suggest that $A B A, J A$, and $S A$ together with ethylene are modulating some of the abiotic stress defense responses on sun-exposed fruit during photooxidative and heat stress on the tree.

Keywords: sunburn, sunscald, ACC, abiotic stress, ABA, jasmonic acid, auxin, ethylene

\section{INTRODUCTION}

Plants are sensitive to environmental stresses such as chilling, high light, supra-optimal temperatures, drought and salinity, among others. These conditions are major limiting factors for growth and geographic distribution (Boyer, 1982). To face various environmental stresses, plants adapt through a range of physiological and biochemical changes. Although the response of plants 
to abiotic stress depends on various factors, plant hormones are considered the most important endogenous substances that modulate physiological and molecular responses, key for plant survival as sessile organisms (Wolters and Jurgens, 2009; Vob et al., 2014; Wani et al., 2016).

In order to survive under changing environments, plants need to regulate their growth and development (Wolters and Jurgens, 2009). Phytohormones, a diverse group of signaling molecules found in small quantities in cells, mediate this regulation. Their pivotal roles in promoting plant acclimation through modifying growth, development, source/sink transitions, and allocation of nutrients have been well established (Fahad et al., 2015). Phytohormones act at their site of synthesis or elsewhere in the plant after being transported (Peleg et al., 2011; Wani et al., 2016). Moreover, they are of key importance in plant development and phenotypic plasticity. They include auxin (IAA), abscisic acid (ABA), ethylene (ET), salicylic acid (SA), and jasmonates (JAs). Some phytohormones, such as ABA, have been identified as stress hormones. ABA plays critical roles in plant development: maintenance of seed dormancy, inhibition of germination, growth regulation, stomatal closure, fruit abscission, besides mediating abiotic and biotic stress responses (Yang et al., 2011). Kim et al. (2016) reported that JA has a major role in fungal infection, as well as modulating other abiotic stress (low and high temperature, ozone, and wounding) response mechanisms, and growth and development processes such as flowering, tuber formation, and regulation of tendrils (Kim et al., 2016).

According to Brodersen et al. (2005), SA is a stress hormone found in many plant species with a key role in the hypersensitive response (HR) or systemic acquired resistance (SAR). In addition to this defense mechanism, SA can modulate other physiological responses such as thermogenesis, ion absorption, and programmed cell death. As other phytohormone, ethylene (ET), as mediator in the senescence process, is also related to diverse abiotic and biotic stresses responses. This phytohormone is involved in different phases of plant growth as leaf and petal abscission, fruit ripening, and flower senescence.

Auxin is one of the most multi-functional phytohormone and is vital not only for plant growth and development but also for governing and/or coordinating plant growth under stress conditions (Kazan, 2013; Wani et al., 2016). Though there has been a recent upsurge in our understanding of auxin regulation of plant growth and development, its role as a regulator of stress response is still little understood. However, auxin stimulates the transcription of a large number of genes called primary auxin response genes, and these genes have been identified and characterized in several plant species including rice, Arabidopsis, and soybean (Javid et al., 2011). Auxin is regarded as an influential constituent of defense responses via regulation of numerous genes and mediation of crosstalk between abiotic and biotic stress responses (Fahad et al., 2015; Wani et al., 2016). However, identification of novel genes involved in stress responses may prove to be a vital target for engineering abiotic stress tolerance in important crops.

Apple (Malus domestica Borkh.) is a major fruit crop grown in Chile. The production area has a semi-arid climate with high solar irradiance and elevated temperature during the growing season. This climate lead unavoidably to abiotic stress in fruit trees causing biochemical and physiological changes in fruit tissues resulting in visible and invisible sun damage symptoms caused by photooxidative and heat stress (Torres et al., 2006), some of which are tissue discoloration and browning of the fruit surface directly exposed to sunrays, changes in fruit shape and texture, decrease of water content, and increase is sugar concentration (Torres et al., 2013).

Upon sun exposure, up-regulation of antioxidants systems, such as the ascorbate-glutathione cycle (Ma and Cheng, 2003; Torres et al., 2006; Chen et al., 2008), phenylpropanoids and carotenoids synthesis and accumulation (Ma and Cheng, 2003; Torres et al., 2006; Chen et al., 2008; Felicetti and Schrader, 2008; Yuri et al., 2010; Tartachnyk et al., 2012), and accumulation of compatible osmolytes occurs (Torres et al., 2013). These and others defense mechanisms during high light and heat stress on fruit are most certain regulated by phytohormones, transducing stress signals throughout tissues, although limited information is available (on apple fruit). Torres et al. (2013) found significantly higher 'stress' ethylene early in the season during sun damage development. Whether this occurs by ET crosstalk with other phytohormones known to modulate abiotic stress responses in plants is still unknown.

The aim of this work was to understand how stress phytohormones interact during photooxidative stress leading to sun-related disorders pre- and post-harvest on apples in order to build strategies to enhances crop resistance.

\section{MATERIALS AND METHODS}

\section{Plant Material and Fruit Sampling}

Apples (Malus domestica Borkh.) cv. Granny Smith from two commercial orchards located in San Clemente, Maule valley, Chile ('Quilpue,' $35^{\circ} 30^{\prime} 26,92^{\prime \prime}$ S., $71^{\circ} 25^{\prime} 25,07^{\prime \prime} \mathrm{W}, 229$ m.a.s.l, and 'Los Lirios', $35^{\circ} 31^{\prime} 18,13^{\prime \prime}$ S., $71^{\circ} 26^{\prime} 32,25^{\prime \prime}$ W, 230 m.a.s.l) were sampled during 2013/2014 season. Fruit with different sun exposures to direct sunlight and photooxidative injury levels were sampled every 15 days from 75 to 165 days after full bloom (DAFB), and after commercial harvest (165 DAFB) during cold storage at $1^{\circ} \mathrm{C}(>90 \% \mathrm{RH})$ for 120 days. At each time point, 4 replicates of 5 fruits each per sun injury category (= treatments) were used for statistical analysis.

Fruit classification was done according the following categories: 'Non-exposed' (NE), tissue non-exposed to direct sunlight (shaded); 'Exposed' (EX), tissue exposed to direct sunlight without visual symptoms of sun-damage; 'Moderate' (Mod), discolored tissue showing yellowing and browning classified as moderate sun-injury symptoms.

Within $24 \mathrm{~h}$ of sampling fruit, peel (4-5 layers of epidermal and hypodermal cells, $<1 \mathrm{~mm}$ thick) of 5 fruit per category (composite sample) was removed with a scalpel, immediately flash frozen with liquid $\mathrm{N} 2$, and stored at $-80^{\circ} \mathrm{C}$ until analysis. 


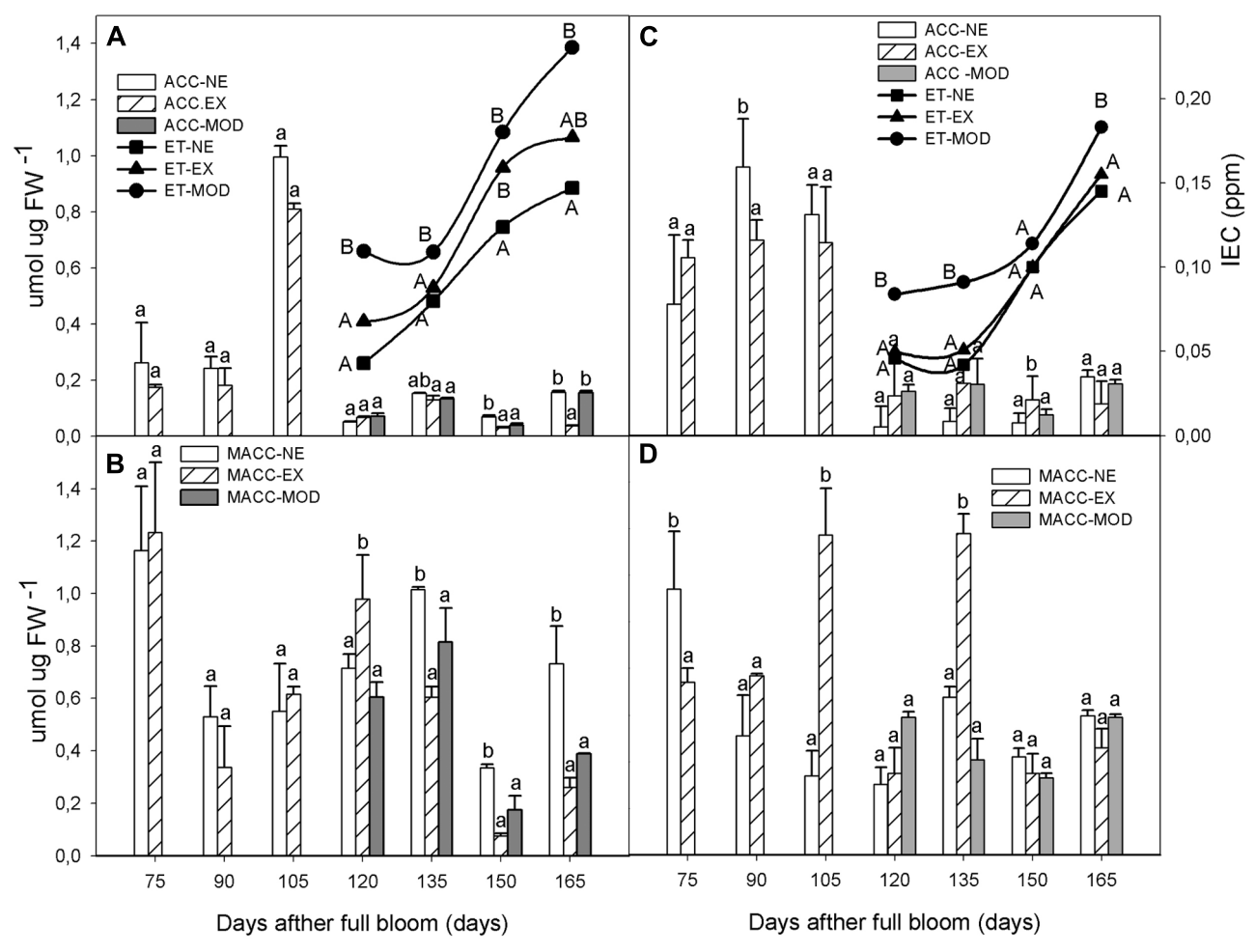

FIGURE 1 | Internal ethylene concentration (ET), free ACC and Malonyl-ACC (MACC) interactions in apple skin during fruit development of non-exposed (NE), exposed (EX), and moderate sun-damaged (MOD) fruit from orchards Quilpue (A,B) and Los Lirios (C,D), Maule Region, Chile. Different upper-case (ET) and lower-case (ACC and MACC) letters indicate statistical difference $(P \leq 0.05)$ between sun damage levels at each time point. Values represent means \pm SE of 3 biological replicates.

\section{Auxin, Jasmonic Acid, Salicylic Acid, and Abscisic Acid Determinations}

Tissue extraction was carried by a modified method from Gómez-Cadenas et al. (2002) and Durgbanshi et al. (2005) Frozen tissue $(0.5 \mathrm{~g} \mathrm{FW}-1)$ was extracted with $80 \%$ methanol $(5 \mathrm{~mL})$ using mortar and pestle, after centrifugation $(5.000 \mathrm{~g} \times 10 \mathrm{~min})$ supernatant was dried using $\mathrm{N}_{2}$ gas. After re-suspension using $2 \mathrm{~mL}$ water:pure diethyl-ether (1:1) samples are shaken for $1 \mathrm{~min}$. The diethyl-ether fraction was subsequently dried using $\mathrm{N}_{2}$ gas and re-suspended in $10 \%$ methanol $(200 \mu \mathrm{L})$. A $10 \mu \mathrm{L}$ volume was injected to a UHPLC-mass spectrometer (Orbitrap, Thermo Scientific, Waltham, MA, United States). After 20 min run, quantification was carried out using pure standards of indole-3-acetic acid, ( \pm -abscisic acid (ABA), ( \pm )-jasmonic acid, and salicylic acid (Sigma-Aldrich, St. Louis, MO, United States) using Xcalibur v.2.13 (Thermo Scientific, Waltham, MA, United States).

\section{Internal Ethylene Concentration (IEC)}

Internal ethylene concentration (IEC) was performed according to Hernandez et al. (2014). One $\mathrm{ml}$ of gas from the core of the fruit was taken through the calix end and then injected into a Hewlett Packard, Series II HP 5890 gas chromatograph equipped with a packed column [Porapak $\mathrm{Q}\left(80^{\circ} \mathrm{C}\right)$ ] and a flame ionization detector with Helium as a carrier gas. Ethylene concentration was determined using a proper standard curve.

\section{ACC and Malonyl-ACC (MACC) Concentrations}

ACC and MACC were determined according to Bulens et al. (2011). Around 0.25 g FW-1 frozen ground peel was extracted with $5 \%(\mathrm{v} / \mathrm{v})$ sulfosalicylic acid (SSA). After vortexing the mixture, it was shaken at $4^{\circ} \mathrm{C}$ for $30 \mathrm{~min}$. The extract was then centrifuged at $3.090 \times g$ at $4^{\circ} \mathrm{C}$. One and half $\mathrm{mL}$ of supernatant was used to determine free ACC. $20 \mathrm{mM} \mathrm{HgCl} 2(0.2 \mathrm{~mL})$ were added to the aqueous sample in a glass vial. After sealing it, a mixture of $\mathrm{NaOH}-\mathrm{NaOCl}(2: 1, \mathrm{v} / \mathrm{v})(0.1 \mathrm{~mL})$ is injected. After 4 min and vortexing, a $1 \mathrm{~mL}$ ethylene sample was taken from the vial and injected into a Hewlett Packard, Series II HP 5890 gas chromatograph equipped with a packed column [Porapak Q $\left.\left(80^{\circ} \mathrm{C}\right)\right]$ and a flame ionization detector.

For total ACC another $1.5 \mathrm{~mL}$ of supernatant of the extract was subjected to acidic hydrolysis using $6 \mathrm{M} \mathrm{HCl}(0.2 \mathrm{ml})$ for $3 \mathrm{~h}$ in a water bath at $99^{\circ} \mathrm{C}$. The sample was then centrifuged at $22.000 \times g$ for $5 \mathrm{~min}$ and the supernatant collected. $0.1 \mathrm{~mL}$ of supernatant diluted with $0.6 \mathrm{~mL}$ of distilled water was mixed with $20 \mu \mathrm{L}$ ACC standard solution $(50 \mu \mathrm{M})$, as well as $10 \mathrm{mM} \mathrm{HgCl} 2$ $(0.1 \mathrm{~mL})$ to proceed with the sealing of the glass vial. A mixture of $\mathrm{NaOH}-\mathrm{NaOCl}(2: 1, \mathrm{v} / \mathrm{v})(0.1 \mathrm{~mL})$ is injected to the vial. After 
$4 \mathrm{~min}$ and vortexing, a $1 \mathrm{~mL}$ ethylene sample was taken from the vial and injected into a Hewlett Packard, Series II HP 5890 gas chromatograph equipped with a packed column [Porapak $\left.\mathrm{Q}\left(80^{\circ} \mathrm{C}\right)\right]$ and a flame ionization detector. MACC is calculated subtracting Total ACC with free ACC.

\section{Experiment Layout and Statistical Analysis}

Data analyses was carried out using one-way analysis of variance (ANOVA), after normality assumptions were met (Levene's test). Sun exposure and sun injury categories at each time point were considered treatments. Mean differences were separated using Tukey's multiple range test (HSD, $P \leq 0.05$ ). GLM procedures using SAS statistical software (version 8.02; SAS Institute, Cary, NC, United States) were used.

\section{RESULTS}

\section{Characterization of Phytohormones during Fruit Development}

After 120 DAFB, when Mod symptoms developed, ET concentration increased ( $26 \%$ in average in both sites) compared to NE and EX levels (Figures 1A,C), although not statistically significant. As expected, in all categories ET levels increased exponentially as fruit matured (Figures 1A,C).

Regarding ACC levels, prior to Mod symptoms appearance, tissue showed higher ACC concentrations regardless of sun exposure (105 DAFB; Figures 1A,C). After this time point (at 120 DAFB), ACC levels decreased more than 90\% until 165 DAFB in all sun exposure categories.

MACC were higher than ACC levels throughout fruit development varying between sun exposure categories (Figures 1B,D). In Quilpue site, the highest were observed early in the season at 75 DAFB, decreasing thereafter (Figure 1B). Non-sun injured tissue (NE, EX) had, in general, higher MACC levels than Mod category (Figures 1B,D). After 120 DAFB, MACC remained significantly higher than ACC until 165 DAFB, regardless of sun exposure (Figure 1).

Although unexposed tissue (NE) tended to have higher levels of IAA early in the season compared to EX, it was only statistically significant at 75, 105 DAFB, and after 135 DAFB (Figures 2A,B). Sun-injured tissue (Mod) had, in general, lower IAA levels compared to NE, but similar to those of EX's (Figures 2A,B). On $\mathrm{NE}$ and EX, IAA decreased as the season progressed, which was not observed in Mod category (Figures 2A,B).

There was a significant increase (around twofold) in ABA levels when sun injury appeared (Mod) after 120 DAFB, although not always statistically different between categories (Figures 2C,D). In $\mathrm{NE}$ and $\mathrm{EX}, \mathrm{ABA}$ concentrations remained stable throughout fruit development (Figures 2C,D). At 120 $\mathrm{DAFB}, \mathrm{ABA}$ as well as ET where significantly higher in Mod category compared to NE and EX (Figures 2C,D).

Jasmonic acid remained at a low level throughout fruit development (Figures 3A,B). As well as ABA, SA, and ET, JA was significantly higher ( $75 \%$ in average) in Mod tissue, in both experimental sites, compared to $\mathrm{NE}$ and $\mathrm{EX}$, and decreased (44\% in average) toward harvest (Figures 3A,B). SA showed similar behavior as to ABA during fruit development (Figures 3C,D). When sun injury appeared (Mod) at 120 DAFB, SA was significantly higher in this tissue compared to NE and EX (Figures 3C,D).

\section{Characterization of Phytohormones Post-harvest}

During cold storage after fruit harvest, ET in Mod fruit remained significantly higher than that in EX but only until 75 days into storage (Figure 4). ET peak in Mod fruit occurred as early as 4 weeks prior to that of EX fruit (Figure 4).

In general, IAA concentrations remained low post-harvest $(<200 \mathrm{ng}$ gFW-1) (Figure 4). Although IAA levels were overall $20 \%$ lower in sun injured fruit (Mod) compared to undamaged ones, these were statistically similar, except between 30 and 45 days in 'Los Lirios' site (Figures 4C,D).

Similar to what occurred pre-harvest, ABA levels did not change during cold storage in EX fruit, but differences between EX and Mod tissue, as well as between sites, disappeared postharvest (Figures 5A,B). SA levels remained stabled throughout cold storage in EX and Mod (Figures 5C,D).

Finally, in Quilpue site, JA increased around 12-fold and 7 -fold in EX and Mod, respectively, within 15 and 30 days in EX and Mod, respectively, after fruit was placed in cold storage (Figure 5E). In Los Lirios site, JA level did not have a clear pattern although gradually increased in the first 45 days into cold storage (Figure 5F).

\section{DISCUSSION}

Sun-related physiological disorders such as sun damage on apples (Malus domestica Borkh), are caused by cumulative photooxidative and heat stress during the growing season, causing morphological, physiological, and biochemical changes in fruit tissues (Racsko and Schrader, 2012). Furthermore, this physiological disorder alters fruit quality after cold storage, particularly due to browning of the skin, once low temperature stress has been imposed (Hernandez et al., 2014; Torres et al., 2016).

Phytohormones play a key role modulating different resistance systems against such dangerous conditions (Peleg and Blumwald, 2011; Verma et al., 2016; Wani et al., 2016). In Torres et al. (2013) it is suggested that photooxidative stress response in apple fruit may be, in part, regulated by ethylene. In their study, sun exposed tissue also showed lower relative water content $(<9-10 \%)$ and more negative tissue water potentials $(<28 \%)$ compared to undamaged one, as well as osmolytes synthesis and accumulation (i.e., carbohydrates), indication of dehydration stress and osmoregulation. In fact, dehydration in grapes after harvest has shown to induce genes involved in ET synthesis (ACO), carbohydrates, and polyphenols metabolisms (Rizzini et al., 2009). Furthermore, Bonghi et al. (2012) found that phenylpropanoids were differentially accumulated during post-harvest grape dehydration, i.e., accumulation of flavonols 


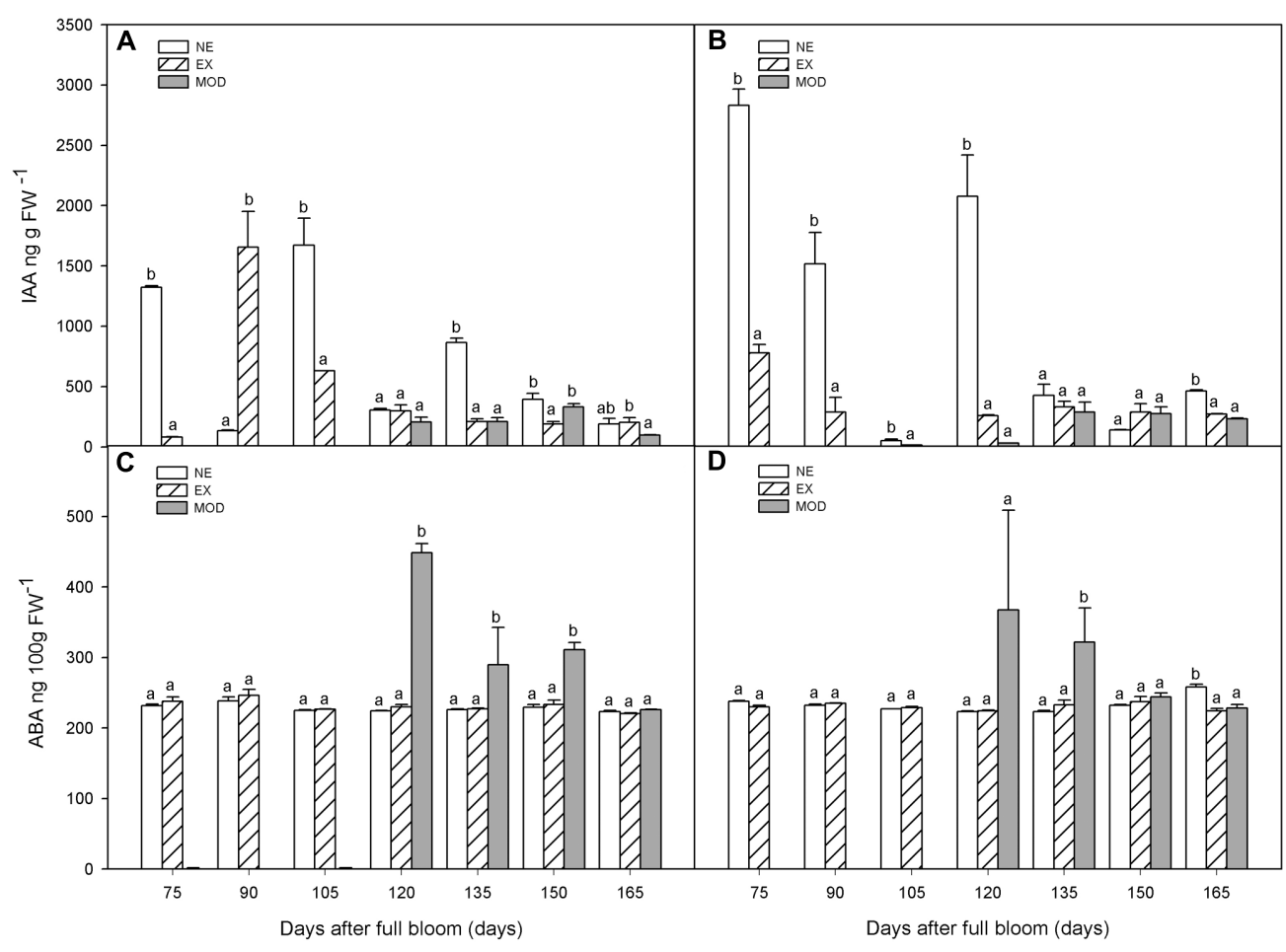

FIGURE 2 | Indol acetic acid (IAA) (A,B) and abscisic acid (ABA) (C,D) concentrations in apple skin during fruit development of non-exposed (NE), exposed (EX), and moderate sun-damaged (MOD) fruit from orchards Quilpue $(\mathbf{A}, \mathbf{C})$ and Los Lirios (B,D), Maule Region, Chile. Different lower-case letters indicate statistical difference $(P \leq 0.05)$ between sun damage levels at each time point. Values represent means \pm SE of 3 biological replicates.

and trans-resveratrol and decreased of flavan-3-ols, procyanidin $\mathrm{B} 1$ and B2. This phenomenon is also a well-known stress defense mechanism against sun exposure on apples (Racsko and Schrader, 2012), and as well as in grapes, specific flavonols are accumulated, such as quercetin glycosides (Yuri et al., 2010).

In agreement with Torres et al. (2013), we also found significantly higher levels of ET early in the season on sun injured fruit (Mod) compare to non-injured ones (Figure 1), which remained for the rest of the growing season and after harvest during cold storage (Figure 4). Moreover, Mod fruit exhibited also an earlier post climacteric decreased of ET, which was around 4 weeks prior to that observed in undamaged fruit (EX) (Figure 4).

Although ET is known for its important role on plant growth and development, and ripening and senescence in climacteric fruit (Yang, 1995; Saltveit, 1999; Paul et al., 2012), sun injured fruit does not ripen earlier than non-injured one. In fact, Schrader et al. (2009) and Torres et al. (2013) found higher flesh firmness in sun injured fruit than in undamaged ones in various apples cultivars. In our study, we found that this phenomenon carries over post-harvest (data not shown), indicating that perhaps sun damage triggers changes in cell wall components that alter tissue softening, as it does on pears (Raffo et al., 2011), or accumulates lignin components that increases tissue firmness (data not shown). In either case, ET could be the signaling molecule. This topic needs to be further studied.
An increase in ACC prior to ET was also observed in sun injured tissue (Figure 1). In rosemary (Rosmarinus officinalis) ACC levels have been positively correlated with solar irradiation, but not to drought (Munné-Bosch et al., 2002).

Auxins have a widely known role regulating plant growth and development (Ostrowski et al., 2016). Nonetheless, only recently studies have also highlighted their role in stress response (Shi et al., 2014; Ostrowski et al., 2016). Auxins in association to ethylene regulate root development and architecture, a key event in drought (Shi et al., 2014) and salinity tolerance (Ostrowski et al., 2016). Auxin has also been found to inhibit ET synthesis (Leyser, 2010; Wang and Irving, 2011). In our research, IAA level was the lowest in sun injured tissue (Mod, Figures 2A,B), which was the one that had the highest ET concentration (Figure 1). These results indicate that IAA and ET are perhaps crosstalking in a signaling network regulating defense responses against photooxidative and heat stress on apple fruit.

In fact, ET and auxin crosstalk in Arabidopsis have been positively correlated with flavonol biosynthesis and accumulation (quercetin and kaempferol) (Lewis et al., 2011), a known photoprotective mechanism in sun exposed apple fruit (Racsko and Schrader, 2012), as well as in other fruit crops (Mahouachi et al., 2014). In particular, the accumulation of quercetin glycosides have been directly correlated with sun damage severity (Felicetti and Schrader, 2010; Yuri et al., 2010; Hernandez et al., 2014; Torres et al., 2016). 


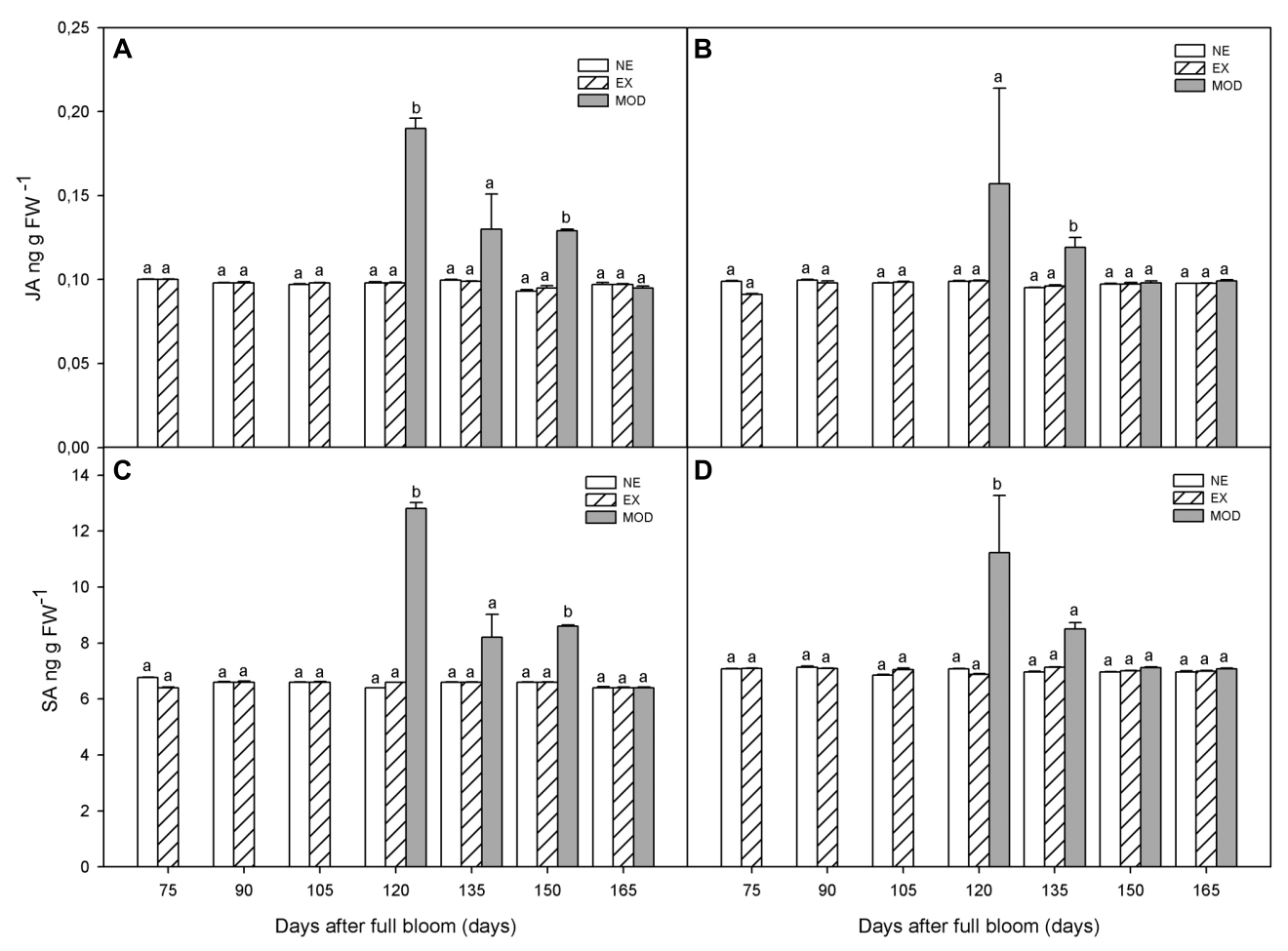

FIGURE 3 | Jamonic acid (JA) (A,B) and salicylic acid (SA) (C,D) concentrations in apple skin during fruit development of non-exposed (NE), exposed (EX), and moderate sun-damaged (MOD) fruit from orchards Quilpue (A,C) and Los Lirios (B,D), Maule Region, Chile. Different lower-case letters indicate statistical difference $(P \leq 0.05)$ between sun damage levels at each time point. Values represent means \pm SE of 3 biological replicates.

In Arabidopsis, both phytohormones induced flavonol accumulation via independent signaling pathways by increasing the abundance of transcripts of different enzymes and transcriptional regulators in their biosynthetic pathway, such as MYB12 (common for both hormones), PAP1 and TTG1. These flavonoids, and in particular quercetin and its derivatives, were found to modulate root growth and auxin basipetal transport (Lewis et al., 2011). Recently, in Arabidopsis shoots was reported that kaempferol 3-O-rhamnoside-7-O-rhamnoside acts as an endogenous inhibitor of auxin transport (Yin et al., 2014). Moreover, light-induced quercetins and kaempferols accumulation in root cells of Arabidopsis causes asymmetrical cell elongation through their accumulation at the side closer to light exposure (Silva-Navas et al., 2016).

The increase or decrease in auxin levels under certain abiotic stresses it seems to be organ and specie specific. Lupinus albus leaves showed low IAA levels after water stress, although the opposite was found in roots (Pinheiro et al., 2011). Mahouachi et al. (2014) found high IAA levels after drought periods on banana plants. In our work, although dehydration stress is present during sun damage development on exposed fruit tissue (Torres et al., 2013), IAA levels where the lowest in sun injured tissue (Mod, Figures 2A,B).

High ET levels on sun injured fruit early in the season (120-135 DAFB) were positively correlated with high ABA concentrations (Figures 2C,D). This could indicate that ABA may be triggering ET synthesis as a stress-response mechanism. In fact, exogenous $A B A$ treatments have shown to increase ET production in many species (Riov et al., 1990; GómezCadenas et al., 1996; Sharp et al., 2000; Jiang and Joyce, 2003) including apples (Lara and Vendrell, 2000). This relation was not observed in undamaged tissue (NE, EX), which is in agreement with Lara and Vendrell (2000) results on Granny Smith flesh. These authors also found an increase in endogenous $\mathrm{ABA}$ together with ACC, MACC, and ET levels, but only in the flesh.

Abscisic acid is known to have an important role in water stress signaling pathways in plants (Zhu, 2002; Wilkinson and Davies, 2010; Mahouachi et al., 2014). This phytohormone not only accumulate under drought conditions, but it appears to have an important role in post-stress recovery of the tissue (MunnéBosch et al., 2002).

In citrus fruit, $A B A$ deficiency resulted in altered water relations in the flavedo, increased water loss, reduced peel firmness and enhanced rot incidence, especially at $12^{\circ} \mathrm{C}$. Under high rate of water loss, ethylene production significantly increased in $\mathrm{ABA}$-mutant fruit, demonstrating that $\mathrm{ABA}$ would negatively regulate water stress-induced ethylene in citrus fruit (Alferez et al., 2005). As indicated by Romero et al. (2013), downstream of ABA signaling, post-harvest water deficit would activate phospholipase activity and trigger lipid catabolism in plasma membranes of citrus fruit. Thus, ABA may be a key 


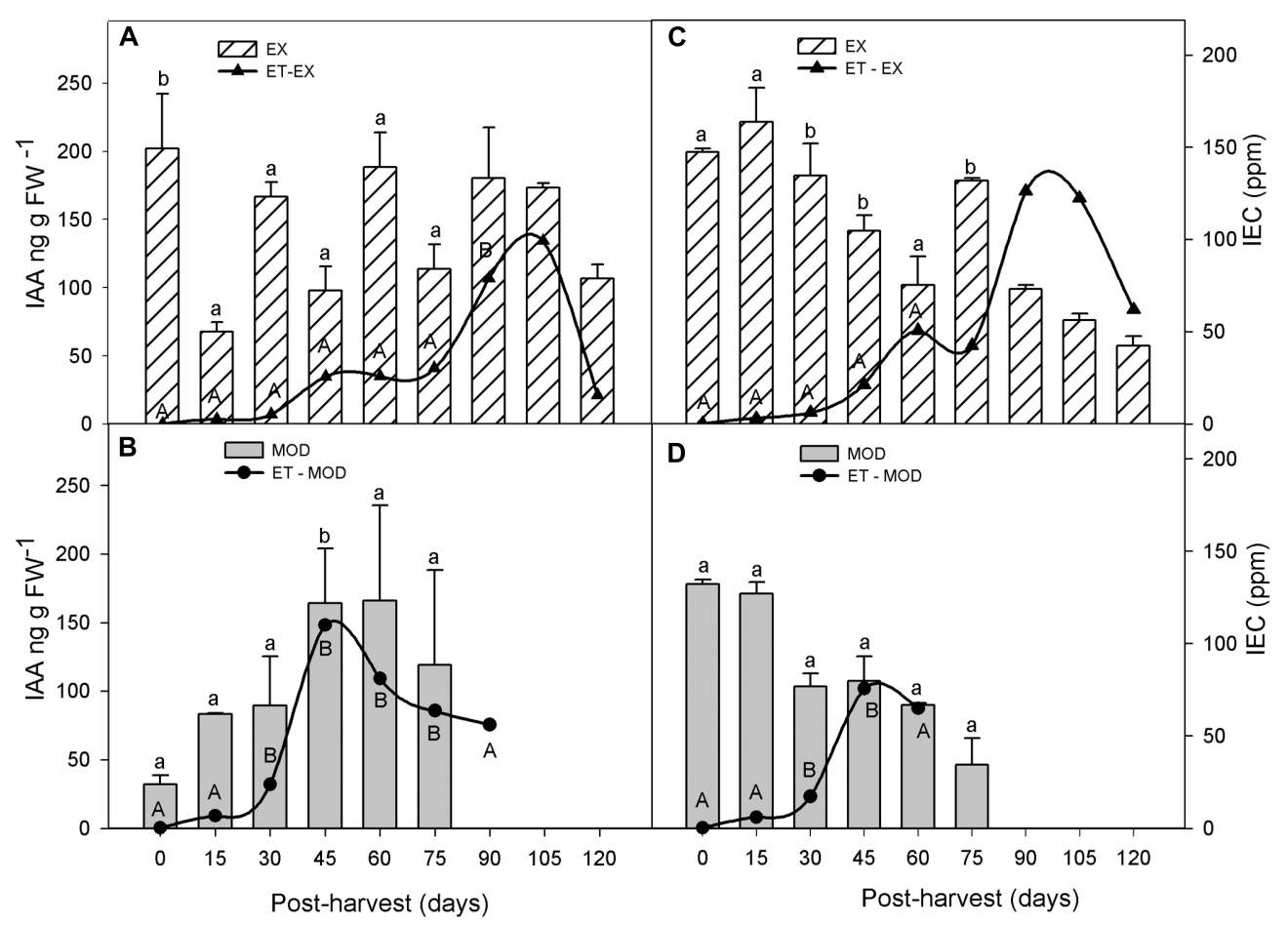

FIGURE 4 | Indol acetic acid (IAA) and ethylene (ET) evolution in apple skin during low temperature storage $\left(0^{\circ} \mathrm{C},>90 \% \mathrm{RH}\right)$ of exposed (EX; $\left.\mathbf{A}, \mathbf{C}\right)$ and moderate sun-damaged (MOD; B,D) fruit from orchards Quilpue (A,B) and Los Lirios (C,D), Maule Region, Chile. Different upper-case and lower-case letters indicate statistical difference $(P \leq 0.05)$ between sun damage levels $(\mathbf{A}$ vs. B and $\mathbf{C}$ vs. D) at each time point. Values represent means $\pm \mathrm{SE}$ of 3 biological replicates. MOD fruit was available until 75 days into cold storage.

regulator of post-harvest water-deficit response mechanisms in this species.

Besides the known role of SA in seed germination, photosynthesis, transpiration, stomatal closure, thermogenesis, cell growth, ion uptake and local and systemic resistance to diseases (Clarke et al., 2004), this phytohormone has been found to have an important role enhancing resistance to various biotic and abiotic stresses, as well as in anti-ripening and anti-senescence mechanisms, all of them important topics for post-harvest management in horticultural crops (Asghari and Aghdam, 2010). Our results showed a burst in SA at 120 DAFB along with ethylene in sun injured tissue (Figures 3C,D). This may indicate that $\mathrm{SA}$ is acting, along with $\mathrm{ET}$ and $\mathrm{ABA}$, in a local tolerance network against photooxidative and heat stress. In fact, according to Asghari and Aghdam (2010) and Asghari and Hasanlooe (2015), there is an initial increase in SA concentration during local and systemic acquired resistance to disease and stress in resistant crops. Similar results have been reported in banana leaves in response to water stress (Mahouachi et al., 2014). SA levels remained stable throughout cold storage (Figures 5C,D) indicating that photo-oxidative and heat stress on fruit while in the tree would be responsible for SA transient increase, but not low temperature stress imposed post-harvest, although free SA has been implicated in cold stress tolerance regulation in Hordeum vulgare, wheat and grape (Kosová et al., 2012; Mutlu et al., 2013). External applications of methyl salicylate on kiwifruit (Actinidia deliciosa) has shown to decrease ethylene production, fruit softening, and loss of ascorbic acid during cold storage. According to Zhang et al. (2003), this is a consequence of lower ACC synthase and AA oxidase, key enzymes in the last step of ET synthesis. In addition, SA hindered ethylene production in cultured pear cells, mung bean hypocotyls, pear tissue disks, carrot cell suspension cultures, among others (Babalar et al., 2007).

Jasmonic acid is generally considered a systemic signal transducer for many physiological processes in the plant related to vegetative growth, cell cycle regulation, senescence, fruit ripening, and biosynthesis of many plant secondary metabolites, among others (Zhao et al., 2005; Sharma and Laxmi, 2016). According to Gill et al. (2013), Guo et al. (2013), Zhao et al. (2013), Dar et al. (2015), and Kazan (2015) JA induces the production of different chemicals involved in detoxification and redox balance in response to insect-driven wounding, pathogen attack, and environmental stresses, such as low temperature, salinity, heavy metal toxicity and latest, heat stress tolerance. Some of these are: proteinase inhibitors, antimicrobial secondary compounds, antioxidants, pathogenesis-related and cellular protection molecules, including proteins (Pauwels and Goossens, 2011; Sharma and Laxmi, 2016). The role of JA and ethylene signaling pathways regulating stress response and development processes have been shown to work in collaboration or in an antagonistic way (Zlotek et al., 2016). In contrast, Shinshi 


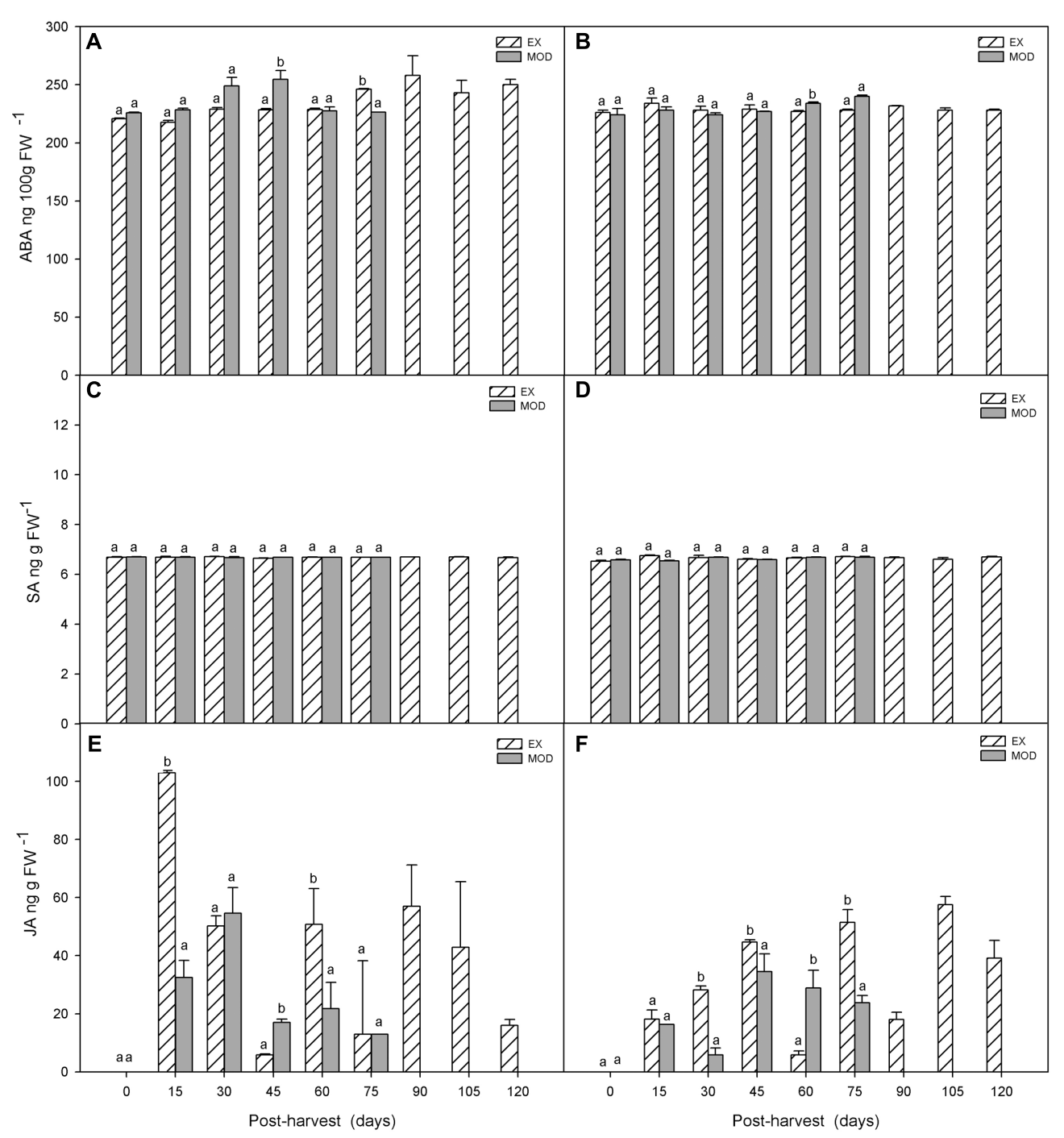

FIGURE 5 | ABA (A,B), SA (C,D) and JA (E,F) concentrations in apple skin during low temperature storage $\left(0^{\circ} \mathrm{C},>90 \% \mathrm{RH}\right)$ of exposed $(\mathrm{EX})$ and moderate sun-damaged (MOD) fruit from orchards Quilpue (A,C,E) and Los Lirios (B,D,F), Maule Region, Chile. Different lower-case letters indicate statistical difference $(P \leq 0.05)$ between sun damage levels at each time point. Values represent means \pm SE of 3 biological replicates. MOD fruit was available until 75 days into cold storage.

(2008) reported that depending on the type of stress, different defense responses can be induced through the sole activation of ethylene, or jasmonate, or both signaling pathways. In our study, JA increased along with ET, ABA, and SA when fruit developed moderate sun injury symptoms (Figures 1A,C, 2C,D, 3A-D). Interestingly, there is evidence showing a coordinated interaction between ABA and JA in response to water stress (dehydration) to protect the plant from it deleterious effects, specifically, JA would have a role regulating $\mathrm{ABA}$ biosynthesis and signaling network (Brossa et al., 2011; De Ollas and Dood, 2016). Changes in relative water content and tissue water potential, indication of dehydration stress, has been previously reported in sun injured fruit (Torres et al., 2013).

In contrast to SA, JA dramatically increased post-harvest (Figures 5E,F), probably signaling chilling injury protective mechanisms involving cryo-protectors, proteinase inhibitors, polyamines, ABA, and antioxidants, among others (Sharma and Laxmi, 2016). In fact, in agreement with our results, Du et al. (2013) reported an increase in JA levels upon exposure of rice to cold stress, as well as drought. In contrast, heat in this species reduced JA and increased IAA levels.

Recently, Hu et al. (2017) reported the induction of JA in response to cold stress in Arabidopsis, as well as the increase in freezing tolerance by exogenous applications of JA. The latest has also been found in other fruit and vegetable species using exogenous methyl JA, in which case an increase in secondary metabolites and antioxidant activity has been reported (ReyesDíaz et al., 2016).

Our findings strongly suggest that there is a crosstalk between stress hormones (ET, JA, SA, ABA) modulating biochemical and 
physiological defense responses and (in some cases) acclimation (Ma and Cheng, 2003; Chen et al., 2008; Racsko and Schrader, 2012; Torres et al., 2013) during photooxidative stress (in the presence of elevated temperature) development on fleshy fruit such as apple. Nevertheless, once the fruit is harvested and subjected to another abiotic stress such as sub-optimal temperature during cold storage, the dramatic increase in JA in the tissue is responsible for activating another set of metabolic responses targeted to confer tolerance (with limited metabolic resources in sun-injured fruit) to this new abiotic stress.

\section{CONCLUSION}

Photooxidative and heat stress on fruit tissue, leading to sun injury development, trigger a plethora of defense responses including antioxidant metabolites and enzymes as well as multiple secondary metabolites. Ethylene, abscisic acid, jasmonic acid and salicylic acid are differentially modulating stress response during this abiotic stress events that ultimately lead to losses in productivity and quality of the final product. Sunlight is causing IAA to decrease on sun exposed tissue while ET, ABA, JA, and SA increase dramatically on tissue that develops sun injury symptoms signaling photooxidative, heat and dehydration stress-defense mechanisms all together. A clear crosstalk between all these phytohormones are modulating the biochemical, physiological and structural changes in fruit tissue exposed to direct sunlight, which involve, initially, up-regulation

\section{REFERENCES}

Alferez, F., Sala, J. M., Sanchez-Ballesta, M. T., Mulas, M., Lafuente, M. T., and Zacarias, L. (2005). A comparative study of the postharvest performance of an ABA-deficient mutant of oranges: I. Physiological and quality aspects. Postharvest Biol. Technol. 37, 222-231. doi: 10.1016/j.postharvbio.2005.05.010

Asghari, M., and Aghdam, S. (2010). Impact of salicylic acid on post-harvest physiology of horticultural crops. Trends Food Sci. Technol. 21, 502-509. doi: 10.1016/j.tifs.2010.07.009

Asghari, M., and Hasanlooe, A. R. (2015). Interaction effects of salicylic acid and methyl jasmonate on total antioxidant content, catalase and peroxidase enzymes activity in "Sabrosa" strawberry fruit during storage. Sci. Hort. 197, 490-495. doi: 10.1016/j.scienta.2015.10.009

Babalar, M., Asghari, M., Talaei, A., and Khosroshahi, A. (2007). Effect of preand postharvest salicylic acid treatment on ethylene production, fungal decay and overall quality of Selva strawberry fruit. Food Chem. 105, 449-453. doi: 10.1016/j.foodchem.2007.03.021

Bonghi, C., Rizzini, F. M., Gambuti, A., Moio, L., Chkaibanc, L., and Tonuttic, P. (2012). Phenol compound metabolism and gene expression in the skin of wine grape (Vitis vinifera L.) berries subjected to partial postharvest dehydration. Postharvest Biol. Technol. 67, 102-109. doi: 10.1016/j.postharvbio.2012.01.002

Boyer, J. S. (1982). Plant productivity and environment. Science 218, 443-448. doi: 10.1126/science.218.4571.443

Brodersen, P., Malinovsky, F. G., Hématy, K., Newman, M. A., and Mundy, J. (2005). The role of salicylic acid in the induction of cell death in Arabidopsis acd11. Plant Physiol. 138, 1037-1045. doi: 10.1104/pp.105.059303

Brossa, R., Lopez-Carbonell, M., Jubany-Mari, T., and Alegre, L. (2011). Interplay between abscisic acid and jasmonic acid and its role in water-oxidative stress in wild-type, ABA-deficient, JA-deficient, and ascorbate-deficient Arabidopsis plants. J. Plant Growth Regul. 30, 322-333. doi: 10.1007/s00344-011-9194-Z

Bulens, I., Van de Poel, B., Hertog, M. L., De Proft, M. P., Geeraerd, A. H., and Nicolaï, B. M. (2011). Protocol: an updated integrated methodology for analysis of antioxidant metabolites and enzymes, secondary metabolites, specifically flavonols, osmolytes (carbohydrates, aminoacids, etc.). Despite all this metabolic machinery engaged through a complex hormonal regulation to protect the tissue from excess light and heat, oxidative stress depletes key antioxidants such as ascorbate and glutathione, leaving the tissue unable to acclimate to those harsh environmental conditions in the field, or later defense himself to chilling stress during cold storage.

\section{AUTHOR CONTRIBUTIONS}

CT: experimental and field design, discussion of results. GS: conducted field experiments and statistical analysis. BK: manuscript writing and discussion of results.

\section{FUNDING}

This work was supported by the 'Fondo de Ciencia y Tecnología' (Fondecyt Regular \#1131138, Fondequip \# EQM-120191, and Fondecyt Postdoctorado \#3170276).

\section{ACKNOWLEDGMENTS}

We wish to thank Abigail Bustamante and Miguel Valenzuela for their great and critical work in the field and laboratory.

of metabolites and enzyme activities of ethylene biosynthesis. Plant Methods 7:17. doi: 10.1186/1746-4811-7-17

Chen, L. S., Li, P., and Cheng, L. (2008). Effects of high temperature coupled with high light on the balance between photooxidation and photoprotection in the sun-exposed peel of apple. Planta 228, 745-756. doi: 10.1007/s00425-0080776-3

Clarke, S. M., Mur, L. A., Wood, J. E., and Scott, I. M. (2004). Salicylic acid dependent signaling promotes basal thermotolerance but is not essential for acquired thermotolerance in Arabidopsis thaliana. Plant J. 38, 432-447. doi: 10.1111/j.1365-313X.2004.02054.x

Dar, T. A., Uddin, M., Khan, M. M. A., Hakeem, K. R., and Jaleel, H. (2015). Jasmonates counter plant stress: a review. Environ. Exp. Bot. 115, 49-59. doi: 10.1016/j.envexpbot.2015.02.010

De Ollas, C., and Dood, I. C. (2016). Physiological impacts of ABA-JA interactions under water-limitation. Plant Mol. Biol. 91, 641-650. doi: 10.1007/s11103-0160503-6

Du, H., Liu, H., and Xiong, L. (2013). Endogenous auxin and jasmonic acid levels are differentially modulated by abiotic stresses in rice. Front. Plant Sci. 4:397. doi: 10.3389/fpls.2013.00397

Durgbanshi, A., Arbona, V., Pozo, O., Miersch, O., Sancho, J. V., and GomezCadenas, A. (2005). Simultaneous determination of multiple phytohormones in plant extracts by liquid chromatography-electrospray tandem mass spectrometry. J. Agric. Food Chem. 53, 8437-8442. doi: 10.1021/jf050884b

Fahad, S., Nie, L., Chen, Y., Wu, C., Xiong, D., Saud, S., et al. (2015). Crop plant hormones and environmental stress. Sustain. Agric. Rev. 15, 371-400. doi: 10.1007/978-3-319-09132-7_10

Felicetti, D. A., and Schrader, L. E. (2008). Changes in pigment concentrations associated with the degree of sunburn browning of 'Fuji' apple. J. Am. Soc. Hort. Sci. 133, 27-34.

Felicetti, D. A., and Schrader, L. E. (2010). Postharvest changes in pigment concentrations in 'Fuji' apples with 'Fuji' stain. Sci. Hort. 125, 283-288. doi: 10.1016/j.scienta.2010.04.004 
Gill, S. S., Anjum, N. A., Hasanuzzaman, M., Gill, R., Trivedi, D. K., Ahmad, I., et al. (2013). Glutathione and glutathione reductase: a boon in disguise for plant abiotic stress defense operations. Plant Physiol. Biochem. 70, 204-212. doi: 10.1016/j.plaphy.2013.05.032

Gómez-Cadenas, A., Pozo, O. J., García-Augustín, P., and Sancho, J. V. (2002). Direct analysis of abscisic acid in crude plant extracts by liquid chromatography-electrospray/tandem mass spectrometry. Phytochem. Anal. 13, 228-234. doi: 10.1002/pca.640

Gómez-Cadenas, A., Tadeo, F. R., Talon, M., and Primo-Millo, E. (1996). Leaf abscission induced by ethylene in water-stressed intact seedlings of Cleopatra mandarin requires previous abscisic acid accumulation in roots. Plant Physiol. 112, 401-408. doi: 10.1104/pp.112.1.401

Guo, J., Chen, Y. Z., Li, M. S., Shi, L., and Yan, X. F. (2013). Does MYC2 really play a negative role in jasmonic acid-induced indolic glucosinolate biosynthesis in Arabidopsis thaliana? Russ. J. Plant Physiol. 60, 100-107. doi: 10.1134/ S1021443713010020

Hernandez, O., Torres, C., Moya-León, M., Opazo, M., and Razmilic, I. (2014). Roles of the ascorbate-glutathione cycle, pigments and phenolics in postharvest 'sunscald' development on 'Granny Smith' apples (Malus domestica Borkh.). Postharvest Biol. Technol. 87, 79-87. doi: 10.1016/j.postharvbio.2013.08.003

Hu, Y., Jiang, Y., Han, X., Wang, H., Pan, J., and Yu, D. (2017). Jasmonate regulates leaf senescence and tolerance to cold stress: crosstalk with other phytohormones. J. Exp. Bot. 68, 1361-1369. doi: 10.1093/jxb/erx004

Javid, M. G., Sorooshzadeh, A., Moradi, F., Sanavy, S. A. M. M., and Allahdadi, I. (2011). The role of phytohormones in alleviating salt stress in crop plants. Aust. J. Crop Sci. 5, 726-734. doi: 10.1007/s00425-015-2435-9

Jiang, Y., and Joyce, D. C. (2003). ABA effects on ethylene production, PAL activity, anthocyanin and phenolic contents of strawberry fruit. Plant Growth Regul. 39, 171-174. doi: 10.1023/A:1022539901044

Kazan, K. (2013). Auxin and the integration of environmental signals into plant root development. Ann. Bot. 112, 1655-1665. doi: 10.1093/aob/mct229

Kazan, K. (2015). Diverse roles of jasmonates and ethylene in abiotic stress tolerance. Trends Plant Sci. 20, 219-229. doi: 10.1016/j.tplants.2015.02.001

Kim, Y. H., Choi, K. I., Khan, A. L., Waqas, M., and Lee, I. J. (2016). Exogenous application of abscisic acid regulates endogenous gibberellins homeostasis and enhances resistance of oriental melon (Cucumis melo var. L.) against low temperature. Sci. Hort. 207, 41-47. doi: 10.1016/j.scienta.2016.05.009

Kosová, K., Prasil, I. T., Vitamvas, P., Dobrev, P., Motyka, V., Flokova, K., et al. (2012). Complex phytohormone responses during the cold acclimation of two wheat cultivars differing in cold tolerance, winter Samanta and spring Sandra. J. Plant Physiol. 169, 567-576. doi: 10.1016/j.jplph.2011.12.013

Lara, I., and Vendrell, M. (2000). Development of ethylene-synthesizing capacity in preclimacteric apples: interaction between abscisic acid and ethylene. J. Am. Soc. Hort. Sci. 125, 505-512.

Lewis, D. R., Ramirez, M. V., Miller, N. D., Vallabhaneni, P., Ray, W. K., Helm, R. F., et al. (2011). Auxin and ethylene induce flavonol accumulation through distinct transcriptional networks. Plant Physiol. 156, 144-164. doi: 10.1104/pp. 111.172502

Leyser, O. (2010). The power of auxin in plants. Plant Physiol. 155, 501-505. doi: $10.1104 /$ pp.110.161323

Ma, F., and Cheng, L. (2003). The sun-exposed peel of apple fruit has higher xanthophyll cycle-dependent thermal dissipation and antioxidants of the ascorbate-glutathione pathway than the shaded peel. Plant Sci. 165, 819-827. doi: 10.1016/S0168-9452(03)00277-2

Mahouachi, J., López-Climent, M. F., and Gómez-Cadenas, A. (2014). Hormonal and hydroxycinnamic acids profiles in banana leaves in response to various periods of water stress. Sci. World J. 2014:540962. doi: 10.1155/2014/540962

Munné-Bosch, S., López-Carbonell, M., Alegre, L., and Van Onckelen, H. A. (2002). Effect of drought and high solar radiation on 1-aminocyclopropane-1carboxylic acid and abscisic acid concentrations in Rosmarinus officinalis plants. Physiol. Plant. 114, 380-386. doi: 10.1034/j.1399-3054.2002.1140307.x

Mutlu, S., Karadagoglu, O., Atici, O., and Nalbantoglu, B. (2013). Protective role of salicylic acid applied before cold stress on antioxidative system and protein patterns in barley apoplast. Biol. Plant. 57, 507-513. doi: 10.1007/s10535-0130322-4

Ostrowski, M., Ciarkowska, A., and Jakubowska, A. (2016). The auxin conjugate indole-3-acetyl-aspartate affects responses to cadmium and salt stress in Pisum sativum L. J. Plant Physiol. 191, 63-72. doi: 10.1016/j.jplph.2015.11.012
Paul, V., Pandey, R., and Srivastava, G. (2012). The fading distinctions between classical patterns of ripening in climacteric and non-climacteric fruit and the ubiquity of ethylene-an overview. J. Food Sci. Technol. 49, 1-21. doi: 10.1007/ s13197-011-0293-4

Pauwels, L., and Goossens, A. (2011). The JAZ proteins: a crucial interface in the jasmonate signaling cascade. Plant Cell 23, 3089-3100. doi: 10.1105/tpc.111. 089300

Peleg, Z., and Blumwald, E. (2011). Hormone balance and abiotic stress tolerance in crop plants. Curr. Opin. Plant Biol. 14, 290-295. doi: 10.1016/j.pbi.2011. 02.001

Peleg, Z., Reguera, M., Tumimbang, E., Walia, H., and Blumwald, E. (2011). Cytokinin-mediated source/sink modifications improve drought tolerance and increase grain yield in rice under water-stress. Plant Biotechnol. J. 9, 747-758. doi: 10.1111/j.1467-7652.2010.00584.x

Pinheiro, C., António, C., Ortuño, M. F., Dobrev, P. I., Hartung, W., ThomasOates, J., et al. (2011). Initial water deficit effects on Lupinus albus photosynthetic performance, carbon metabolism, and hormonal balance: metabolic reorganization prior to early stress responses. J. Exp. Bot. 62, 49654974. doi: 10.1093/jxb/err194

Racsko, J., and Schrader, L. E. (2012). Sunburn of apple fruit: historical background, recent advances and future perspectives. Crit. Rev. Plant Sci. 31, 455-504. doi: 10.1080/07352689.2012.696453

Raffo, M. D., Ponce, N. M., Sozzi, G. O., Vicente, A. R., and Stortz, C. A. (2011). Compositional changes in 'Bartlett' pear (Pyrus communis L.) cell wall polysaccharides as affected by sunlight conditions. J. Agric. Food Chem. 59, 12155-12162. doi: 10.1021/jf203950d

Reyes-Díaz, M., Lobos, T., Cardemil, L., Nunes-Nesi, A., Retamales, J., Jaakola, L., et al. (2016). Methyl Jasmonate: an alternative for improving the quality and health properties of fresh fruits. Molecules 21:E567. doi: 10.3390/ molecules21060567

Riov, J., Dagan, E., Goren, R., and Yang, S. F. (1990). Characterization of abscisic acid-induced ethylene production in citrus leaf and tomato fruit tissues. Plant Physiol. 92, 48-53. doi: 10.1104/pp.92.1.48

Rizzini, F. M., Bonghi, C., and Tonutti, P. (2009). Postharvest water loss induces marked changes in transcript profiling in skins of wine grape berries. Postharvest Biol. Biotechnol. 52, 247-253. doi: 10.1016/j.postharvbio.2008. 12.004

Romero, P., Gandía, M., and Alférez, F. (2013). Interplay between ABA and phospholipases $\mathrm{A}(2)$ and $\mathrm{D}$ in the response of citrus fruit to postharvest dehydration. Plant Physiol. Biochem. 70, 287-294. doi: 10.1016/j.plaphy.2013. 06.002

Saltveit, M. E. (1999). Effect of ethylene on quality of fresh fruit and vegetables. Postharvest Biol. Technol. 15, 279-292. doi: 10.1016/S0925-5214(98) 00091-X

Schrader, L. E., Zhang, J., Sun, J., Xu, J., and Elfving, D. C. (2009). Postharvest changes in internal fruit quality in apples with sunburn browning. J. Am. Soc. Hort. Sci. 134, 148-155.

Sharma, M., and Laxmi, A. (2016). Jasmonates: emerging players in controlling temperature stress tolerance. Front. Plant Sci. 6:1129. doi: 10.3389/fpls.2015. 01129

Sharp, R. E., Le Noble, M. E., Else, M. A., Thorne, E. T., and Gherardi, F. (2000). Endogenous ABA maintains shoot growth in tomato independently of effect on plant water balance: evidence for an interaction with ethylene. J. Exp. Bot. 51, 1575-1584. doi: 10.1093/jexbot/51.350.1575

Shi, H., Chen, L., Ye, T., Liu, X., Ding, K., and Chan, Z. (2014). Modulation of auxin content in Arabidopsis confers improved drought stress resistance. Plant Physiol. Biochem. 82, 209-217. doi: 10.1016/j.plaphy.2014.06.008

Shinshi, H. (2008). Ethylene-regulated transcription and crosstalk with jasmonic acid. Plant Sci. 175, 18-23. doi: 10.1016/j.plantsci.2008.03.017

Silva-Navas, J., Moreno-Risueno, M. A., Manzano, C., Téllez-Robledo, B., NavarroNeila, S., Carrasco, V., et al. (2016). Flavonols mediate root phototropism and growth through regulation of proliferation-to-differentiation transition. Plant Cell 28, 1372-1387. doi: 10.1105/tpc.15.00857

Tartachnyk, I., Kuckenberg, J., Yuri, J. A., and Noga, G. (2012). Identifying fruit characteristics for non-invasive detection of sunburn in apple. Sci. Hort. 134, 108-113. doi: 10.1016/j.scienta.2011.11.009

Torres, C. A., Andrews, P. K., and Davies, N. M. (2006). Physiological and biochemical responses of fruit exocarp of tomato (Lycopersicon esculentum 
Mill.) mutants to natural photo-oxidative conditions. J. Exp. Bot. 57, 1933-1947. doi: $10.1093 /$ jxb/erj136

Torres, C. A., Hernandez, O., Moya-León, M. A., Razmilic, I., and Rudell, D. R. (2016). Antioxidant metabolism and gene expression during "Stain" development on 'Fuji' apples during Cold Storage. Hortscience 51, 1031-1037.

Torres, C. A., Sepulveda, A., González-Talice, J., Yuri, J. A., and Razmilic, I. (2013). Fruit water relations and osmoregulation on apples (Malus domestica Borkh.) with different sun exposures and sun-injury levels on the tree. Sci. Hortic. 161, 143-152. doi: 10.1016/j.scienta.2013.06.035

Verma, V., Ravindran, P., and Kumar, P. P. (2016). Plant hormone-mediated regulation of stress responses. BMC Plant Biol. 16:86. doi: 10.1186/s12870-0160771-y

Vob, U., Bishopp, A., Farcot, E., and Bennett, M. J. (2014). Modelling hormonal response and development. Trends Plant Sci. 19,311-319. doi: 10.1016/j.tplants. 2014.02.004

Wang, Y. H., and Irving, H. R. (2011). Developing a model of plant hormone interactions. Plant Signal. Behav. 6, 494-500. doi: 10.4161/psb.6.4.14558

Wani, S., Kumar, V., Shriram, V., and Sah, S. K. (2016). Phytohormones and their metabolic engineering for abiotic stress tolerance in crop plants. Crop J. 4, 162-176. doi: 10.1016/j.cj.2016.01.010

Wilkinson, S., and Davies, W. J. (2010). Drought, ozone, ABA and ethylene: new insights from cell to plant to community. Plant Cell Environ. 33, 510-525. doi: $10.1111 /$ j.1365-3040.2009.02052.x

Wolters, H., and Jurgens, G. (2009). Survival of the flexible: hormonal growth control and adaptation in plant development. Nat. Rev. Genet. 10, 305-317. doi: $10.1038 / \mathrm{nrg} 2558$

Yang, S. F. (1995). The role of ethylene in fruit ripening. Acta Hort. 398, 167-178. doi: 10.17660/ActaHortic.1995.398.17

Yang, X., Yang, Y.-N., Xue, L.-J., Zou, M.-J., Liu, J.-Y., Chen, F., et al. (2011). Rice ABI5-Like1 regulates abscisic acid and auxin responses by affecting the expression of ABRE-containing genes. Plant Physiol. 156, 1397-1409. doi: $10.1104 /$ pp.111.173427

Yin, R., Han, K., Heller, W., Albert, A., Dobrev, P. I., Zažímalová, E., et al. (2014). Kaempferol 3-O-rhamnoside-7-O-rhamnoside is an endogenous flavonol inhibitor of polar auxin transport in Arabidopsis shoots. New Phytol. 201, 466-475. doi: 10.1111/nph.12558

Yuri, J. A., Neira, A., Quilodran, A., Razmilic, I., Motomura, Y., Torres, C., et al. (2010). Sunburn on apples is associated with increases in phenolic compounds and antioxidant activity as a function of the cultivar and areas of the fruit. J. Food Agric. Environ. 8, 920-925.

Zhang, Y., Chen, K., Zhang, S., and Ferguson, I. (2003). The role of salicylic acid in postharvest ripening of kiwifruit. Postharvest Biol. Technol. 28, 67-74. doi: 10.1016/S0925-5214(02)00172-2

Zhao, J., Davis, L. C., and Verpoorte, R. (2005). Elicitor signal transduction leading to production of plant secondary metabolites. Biotechnol. Adv. 23, 283-333. doi: 10.1016/j.biotechadv.2005.01.003

Zhao, M. L., Wang, J. N., Shan, W., Fan, J. G., Kuang, J. F., Wu, K. Q., et al. (2013). Induction of jasmonate signalling regulators MaMYC2s and theirphysical interactions with MaICE1 in methyl jasmonate-induced chilling tolerance in banana fruit. Plant Cell Environ. 36, 30-51. doi: 10.1111/j.1365-3040.2012. 02551.x

Zhu, J. K. (2002). Salt and drought stress signal transduction in plants. Annu. Rev. Plant Biol. 53, 247-273. doi: 10.1146/annurev.arplant.53.091401.143329

Zlotek, U., Szymanowska, U., Karas, M., and Swieca, M. (2016). Antioxidative and anti-inflammatory potential of phenolics from purple basil (Ocimum basilicum L.) leaves induced by jasmonic, arachidonic and $\beta$-aminobutyric acid elicitation. Int. J. Food Sci. Technol. 51, 163-170. doi: 10.1111/ijfs.12970

Conflict of Interest Statement: The authors declare that the research was conducted in the absence of any commercial or financial relationships that could be construed as a potential conflict of interest.

Copyright (c) 2017 Torres, Sepúlveda and Kahlaoui. This is an open-access article distributed under the terms of the Creative Commons Attribution License (CC BY). The use, distribution or reproduction in other forums is permitted, provided the original author(s) or licensor are credited and that the original publication in this journal is cited, in accordance with accepted academic practice. No use, distribution or reproduction is permitted which does not comply with these terms. 